\title{
Application of Zr-Based Bulk Glassy Alloys to Golf Clubs
}

\author{
Hisashi Kakiuchi ${ }^{1}$, Akihisa Inoue ${ }^{2}$, Masahide Onuki ${ }^{1}$, Yoshishige Takano ${ }^{1}$ and Tetsuo Yamaguchi ${ }^{3}$ \\ ${ }^{1}$ Sports Goods Research Department, Sumitomo Rubber Industries, LTD., Kobe 651-0071, Japan \\ ${ }^{2}$ Institute for Materials Research, Tohoku University, Sendai 980-0812, Japan \\ ${ }^{3}$ Golf Sales and Marketing Department, Sumitomo Rubber Industries, LTD., Kobe 651-0072, Japan
}

Bulk glassy alloys have high tensile strength, while the Young's modulus is lower by 20 to $40 \%$ than those for the corresponding crystalline alloys. These unique mechanical properties are effective to increase the coefficient of restitution at the impact between a golf club and a golf ball. Bulk glassy alloys have in general been produced by the copper mold casting and die casting methods. We have developed a new manufacturing process for $\mathrm{Zr}$-based bulk glassy alloys. By the use of the new process, we have succeeded in producing a glassy $\mathrm{Zr}-\mathrm{Al}-$ $\mathrm{Ni}-\mathrm{Cu}$ alloy in a shell shape with a dimension of about $90 \times 40 \mathrm{~mm}$ and a thickness of $3 \mathrm{~mm}$ for glassy driver golf clubs. It exhibits excellent mechanical properties such as tensile strength of $1700 \mathrm{MPa}$, Young's modulus of $81 \mathrm{GPa}$, and impact fracture toughness of $130 \mathrm{~kJ} / \mathrm{m}^{2}$. These properties are suitable for the material for driver golf club heads. The glassy driver golf club with the shell shape in the impact region was confirmed to have a high coefficient of restitution.

(Received December 1, 2000; Accepted March 15, 2001)

Keywords: bulk glassy alloy, mechanical property, golf club, coefficient of restitution

\section{Antecedents to the Development of Amorphous Al- loys Conventionally Available, and Invention of Bulk Glassy Alloys}

In 1960 , a Au-Si amorphous alloy was produced ${ }^{1)}$ by the rapid solidification process. Since then, interest in this new material has begun to rise. In 1970, the centrifugal quenching process was used to produce a $\mathrm{Pd}-\mathrm{Si}$ amorphous alloy in the form of a tape. This alloy had high strength, and it was concluded that the (high) strength could be enhanced if made amorphous. ${ }^{2)}$ Since then, the material has begun to have a family of extended alloys. In addition to the base alloys of $\mathrm{Fe}$, $\mathrm{Co}$ and $\mathrm{Ni}$, other alloys with $\mathrm{Ti}, \mathrm{Zr}, \mathrm{Nb}$ and the like were used to produce amorphous continuous strips. For example, Feand Co-based amorphous alloys have been put into practical uses as a soft magnetism material. ${ }^{3)}$ In the second half of the 1980 's, a very strong aluminum-based amorphous alloy was produced. In addition, the nano-crystallization in the warm extrusion molding process was used to produce an aluminum alloy with high specific strength, which has now become a practically usable material.

All of the amorphous alloys discovered for a period of approximately thirty years, starting in 1960 and ending in the second half of the 1980's, except for the Pd- and Pt-based ones, required a high cooling rate of approximately $10^{5} \mathrm{~K} / \mathrm{s}$ or more for forming the amorphous phase, with their sizes limited to thin and small ones with a thickness of $50 \mu \mathrm{m}$ or below. To break through any such limitation, some attempts were made to form amorphous powder and strip into a bulk material. Any bulk amorphous alloy that shows useful industrial properties has neither been found nor put into practical use as yet.

Under such situations, many alloys, such as those based on $\mathrm{Mg}$, rare-earth metal ( $\mathrm{Ln}), \mathrm{Zr}, \mathrm{Fe}, \mathrm{Pd}-\mathrm{Cu}$ and $\mathrm{Ti}$, have been found to be capable of producing a several or more millimeter thick bulk glassy alloy at a cooling rate of several hundred K/s or less since $1988 .^{4)}$ Among those alloys, the Zr-based glassy alloys have critical cooling rates $R_{c}$ of 1 to several tens $\mathrm{K} / \mathrm{s}$ and can be produced to a thickness that falls within a range of 30 millimeters. In a history of alloy developments and of patent applications, a family of $\mathrm{Zr}-\mathrm{Al}-$ (Ni, Cu)-based alloys ${ }^{5,6}$ ) was developed in 1990, a family of $\mathrm{Zr}-\mathrm{Ti}-\mathrm{Be}-\mathrm{Ni}-\mathrm{Cu}$-based ${ }^{7)}$ alloys in 1993 and a family of $\mathrm{Zr}-$ $\mathrm{M}-\mathrm{Al}-\mathrm{Ni}-\mathrm{Cu}(\mathrm{M}=\mathrm{Ti}, \mathrm{Nb})$-based alloys ${ }^{8}$ in 1994. All of them have become principal materials, for which basic research and application studies have extended all over the world.

\section{Mechanical Properties of Zr-Based Bulk Glassy Al- loys}

Zr-based bulk glassy alloys are produced in a variety of processes, such as metallic mold casting, water quenching, die-casting and so forth. ${ }^{4)}$ However, for an application to golf clubs, it is necessary to make near-net moldings which should have a heavy weight and a wide area, both conventionally unavailable. To this end, we have newly developed a molding process called the "mold-clamp casting method". (This process will be explained in this paper.) In the Inoue Laboratory of Tohoku University, that method was used to produce a $250 \mathrm{~mm} \times 220 \mathrm{~mm} \times 3 \mathrm{~mm}$ flat sheet of Zr-based glassy alloy. This 3-millimeter-thick sheet sample was used to determine its mechanical properties, thereby clarifying that the glassy alloy has high strength and toughness. The Zr-based bulk glassy alloys show a high level of mechanical properties roughly valued at $1800 \mathrm{MPa}$ in tensile strength, $83 \mathrm{GPa}$ in Young's modulus, $2.2 \%$ in elastic elongation level, $3500 \mathrm{MPa}$ in bending fracture strength, $130 \mathrm{~kJ} / \mathrm{m}^{2}$ in impact fracture toughness, $1000 \mathrm{MPa}$ in bending fatigue strength after completion of $3 \times 10^{4}$ cycles and $70 \mathrm{MPa} \sqrt{\mathrm{m}}$ in notched fracture toughness (Table 1). ${ }^{9)}$ Comparing these values with those of the Ti- $6 \mathrm{Al}-4 \mathrm{~V}$ alloy commercially available suggests that the Zr-based bulk glassy alloys have an excellently high strength as well as toughness properties. In other words, all three of them have approximately 1.6 times the tensile strength, about 10 times the elastic elongation, approximately twice the bending strength, and are equal in impact fracture toughness, about twice in fatigue strength and also equal in the upper limit of 
Table 1 Mechanical properties of 3 millimeters thick Zr-based bulk glassy alloy sheets prepared by the mold-clamp casting method.

\begin{tabular}{|c|c|c|c|c|c|c|c|}
\hline $\begin{array}{l}\text { Alloys } \\
\text { (at\%) }\end{array}$ & $\begin{array}{c}\text { Tensile strength } \\
(\mathrm{MPa})\end{array}$ & $\begin{array}{c}\text { Elastic } \\
\text { elongation } \\
(\%)\end{array}$ & $\begin{array}{l}\text { Young's modulus } \\
\text { (GPa) }\end{array}$ & $\begin{array}{c}\text { Bending fracture } \\
\text { strength } \\
(\mathrm{MPa})\end{array}$ & $\begin{array}{c}\text { Impact fracture } \\
\text { toughness } \\
\left(\mathrm{kJ} / \mathrm{m}^{2}\right)\end{array}$ & $\begin{array}{c}\text { Bending fracture } \\
\text { strength } \\
\left(3 \times 10^{4} \text { cycles }\right) \\
(\mathrm{MPa})\end{array}$ & $\begin{array}{c}\text { Notched fractur } \\
\text { toughness } \\
(\mathrm{MPa} \sqrt{\mathrm{m}})\end{array}$ \\
\hline $\mathrm{Zr}_{55} \mathrm{Al}_{10} \mathrm{Ni}_{5} \mathrm{Cu}_{30}$ & 1700 & 2.3 & 81 & 3100 & 130 & 1050 & 70 \\
\hline $\mathrm{Zr}_{60} \mathrm{Al}_{10} \mathrm{Ni}_{10} \mathrm{Cu}_{20}$ & 1790 & 2.2 & 84 & 3900 & 122 & 1150 & - \\
\hline $\mathrm{Zr}_{58} \mathrm{Ti}_{2} \mathrm{Al}_{10} \mathrm{Ni}_{10} \mathrm{Cu}_{20}$ & 1850 & 2.2 & 85 & 3400 & 135 & 1140 & - \\
\hline
\end{tabular}

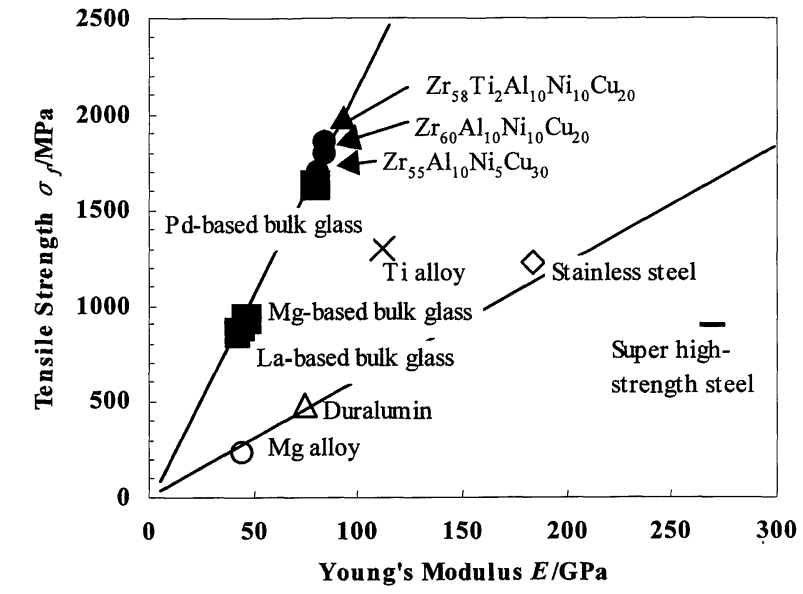

Fig. 1 Tensile strength vs. Young's modulus in bulk glassy alloys. Data relating to typical crystalline alloys commercially available are given for comparison.

notched fracture toughness as compared with the Ti-6Al-4V alloy. The Zr-based bulk glassy alloys are far stronger than Tibased alloys while showing a lower Young's modulus. Nevertheless, they have a larger elastic elongation, showing an elastic energy of twenty times as large as that of a Ti-based alloy. Figure 1 shows the relations among three types of $\mathrm{Zr}$ based glassy alloys in terms of tensile strength and Young's modulus. It also shows the data relating to bulk glassy alloys such as the $\mathrm{Mg}$ - and La-based ones, including crystalline alloys commercially available. The bulk glassy alloys have their mechanical properties belonging to a different group. At an identical Young's modulus, a bulk glassy alloy has a tensile strength of approximately three times, thus showing a much higher strength than that of a crystalline alloy. At the same time, the bulk glassy alloy has a high level of ductility, too. Thus, the mechanical properties of the bulk glassy alloy are unique enough to be unavailable in any crystalline alloys.

\section{Material Factors that Allow a Golf Club to Perform Highly in Let-Fly}

"To fly" is one of the most critical performance requirements for both clubs and balls in a golf game. The main factor that causes a club to let a ball fly is a property of repulsion between them. To improve the repulsion, efforts have been made mainly on modifying the ball materials because the repulsion is largely governed by the energy loss arising from a deformation of the ball. To obtain a higher property of repulsion, however, a technique is required to control the coefficient of restitution (relative speed of two bodies after impacting/their relative speed before impacting). From the viewpoint of energy propagation and mechanical impedance on impact, the present authors researched and found out that the coefficient of restitution would be maximized when the frequency at the minimal value of mechanical impedance (the frequency is generally equivalent to natural frequency) of the impacting body coincides with that of the impacted body. ${ }^{10)}$ For example, a coefficient of restitution was obtained with a finite-degrees-of-freedom model by changing the spring constant of an impacting body. As a result, the coefficient of restitution becomes maximum at the optimum combination of spring constants. In this stage, it was confirmed that the frequency at the minimal value of mechanical impedance of the impacting body coincides with that of the impacted body. Most of the clubs commercially available have a far higher frequency of the head than that of the ball. Designing the head to a lower natural frequency, therefore, was found to suggest possibilities that a high-repulsion club might be developed.

An oscillating system at a freedom degree of 1 has a natural frequency $\left(f_{a}\right)$ subject to a relation of $f_{a} \propto \sqrt{\mathrm{k} / \mathrm{m}}$ between mass $(m)$ and spring constant $(k)$. With the mass kept constant, it will be possible to attain a small natural frequency by decreasing the spring constant. The same applies to structures in general with multiple degrees of freedom. The frequency at which the impacting point at the head has its mechanical impedance minimized could be decreased efficiently by reducing the face rigidity. To that end, it would be conceivable to apply a material having a low Young's modulus while thinning and enlarging the face. At the same time, however, it would inevitably decrease the strength of the face. It has so far been considered impossible, therefore, for any existing materials commercially available to endure an impact force of 1 ton or more while allowing the frequency to decrease sufficiently. Under such circumstances, our attention was drawn by the advent of those bulk glassy alloys which show unusual and unique mechanical properties, i.e. a low Young's modulus and yet extremely high strength and toughness.

\section{Producing a Zr-Based Bulk Glassy Alloy-Applied Golf Club}

Golf clubs commercially available are almost all hollow types, and manufacturing techniques currently available face difficulties in bonding a bulk glassy alloy. We applied the bulk glassy alloy to the face which would contribute most effectively to repulsion. For a glassy alloy, the $\mathrm{Zr}_{55} \mathrm{Al}_{10} \mathrm{Ni}_{5} \mathrm{Cu}_{30}$ alloy which excels most in mechanical properties and glassforming ability was applied. The face with a mass of 60 grams was produced in the "mold-clamp casting method". 


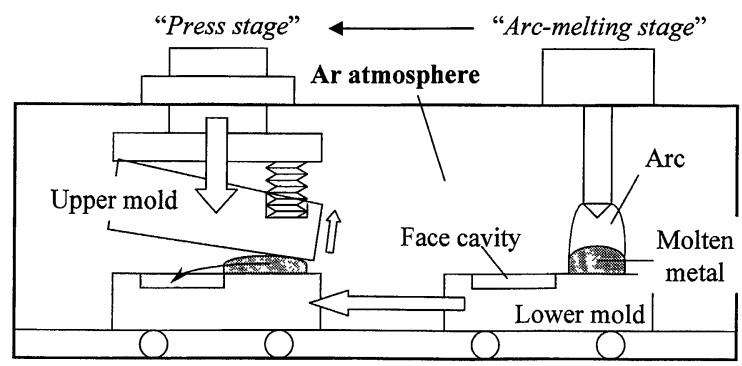

Fig. 2 Schematic diagram of "mold-clamp casting method".

Figure 2 shows the schematic diagram of this newlydeveloped manufacturing process which we have employed. In brief, the mold-clamp casting method has a that melted alloy pressed by a copper mold which is divided into two pieces. The master ingot was prepared by arc-melting the mixture of pure $\mathrm{Zr}, \mathrm{Al}, \mathrm{Ni}, \mathrm{Cu}$ metals in an argon atmosphere. At the first stage, the master ingot is arc-melted on the lower copper mold cooled by water. After sufficient arc-melting, the lower mold moves into the press stage. The inclined upper mold sinks down, and the upper and lower molds shut down while spreading the melted alloy. The sequence of processing is done in an argon atmosphere. Because the flow of the melted alloy does not go out of order, a cold shut does not arise. And, as contact pressure between the melted alloy and the copper mold is comparatively high, it is supposed that cooling rate is high and uniform. Therefore, this process allowed us to obtain a bulk glassy alloy face excelling in its mechanical properties. In other words, the glassy alloy face material of the $\mathrm{Zr}_{55} \mathrm{Al}_{10} \mathrm{Ni}_{5} \mathrm{Cu}_{30}$ alloy made by the ordinary mold casting process had a bending yield strength of $1800 \mathrm{MPa}$ and an impact rupture toughness of $60 \mathrm{~kJ} / \mathrm{m}^{2}$. On the other hand, the mold-clamp casting process industrially permitted a glassy alloy face with the same composition to show such high values as $2200 \mathrm{MPa}$ in bending yield strength and $130 \mathrm{~kJ} / \mathrm{m}^{2}$ in impact rupture toughness while showing the equal elastic modulus value of $81 \mathrm{GPa}$.

The contour of the produced glassy alloy face was properly arranged by machining, and the head body made of Ti-6Al$4 \mathrm{~V}$ had a face provided with a concavity to which the glassy alloy product was bonded. They were completely coupled by an adhesive. The face was through-shaped at any point other than the bonding area so that the low rigidity of the metal glassy alloy face might have its characteristics reflected most effectively.

\section{Evaluating a Golf Club in "Let Fly" Performance and Commercialization}

Figure 3 shows the findings in evaluating the let-fly performance of the golf club as fabricated. To hit a ball on a trial basis, a swing robot was used to measure the let-fly performance-evaluated values when hitting balls under the same conditions. It was compared with an identically shaped head with the same mass, to which the face made of Ti-6Al$4 \mathrm{~V}$ had been bonded. In the figure, the repulsive efficiency is expressed in the ratio of ball's initial speed to head speed. With an identical mass at the head, a high level of repulsive efficiency signifies a high coefficient of restitution. The glassy
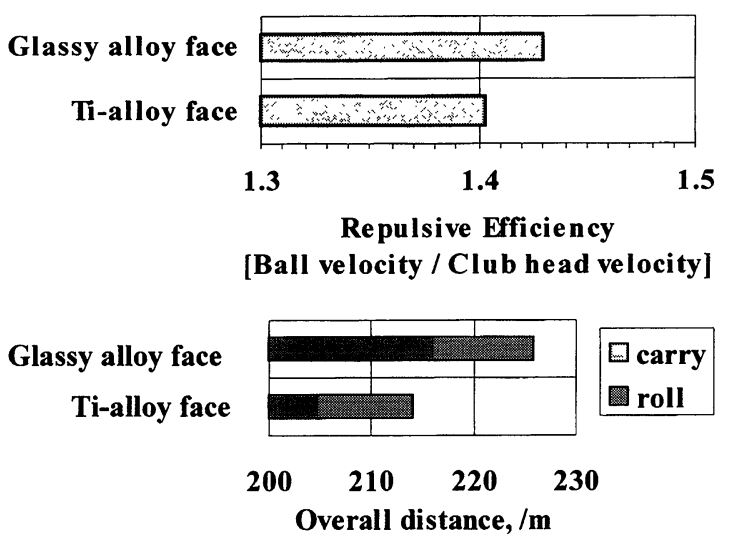

Fig. 3 Results of ball hitting tests with golf-swing robot at The Dunlop Golf Science Center.

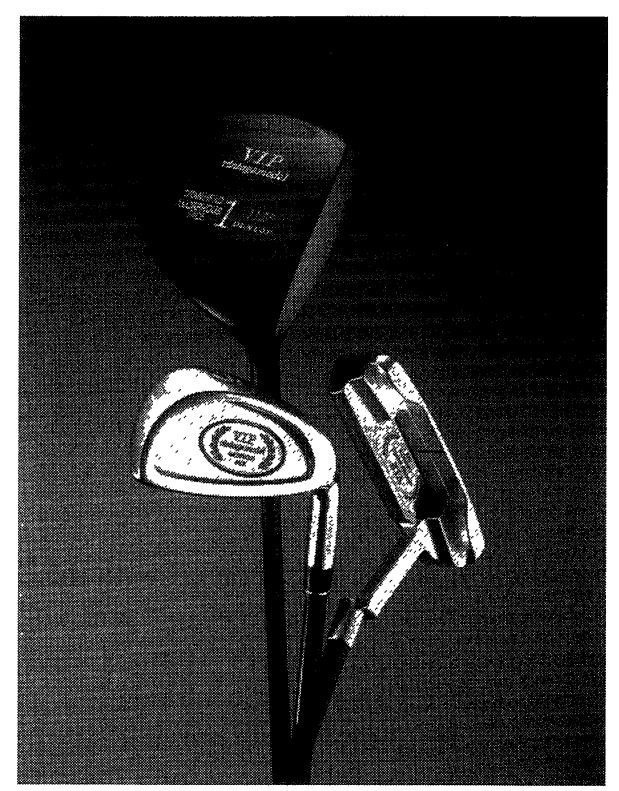

Fig. 4 Applications of $\mathrm{Zr}$-based bulk glassy alloys to golf clubs of wood, iron, putter types.

alloy face had obviously increased a coefficient of restitution at the club head, eventually extending a flying distance by approximately 15 yards $^{11)}(13.7 \mathrm{~m})$ on a carry basis. From its unique mechanical properties, high strength and low Young's modulus, it may be concluded that the $\mathrm{Zr}$-based bulk glassy alloy is a material more suitable for a golf club than any other alloy materials conventionally available.

The golf clubs made of a glassy alloy at the head have been placed on the market by Japan Dunlop under the brand "V.I.P. vintage model AMORPHOUS FACE" since August 21, 1998. This product has been extended comprehensively to iron and putter clubs. Figure 4 shows these products. It has been appraised for its softness in ball-hitting as well as for highrepulsion performance owing to the low Young's modulus and high strength.

\section{Conclusions}

We have tried to develop $\mathrm{Zr}$-based bulk glassy alloy golf clubs to increase the coefficient of restitution. We have suc- 
ceeded in producing a glassy $\mathrm{Zr}-\mathrm{Al}-\mathrm{Ni}-\mathrm{Cu}$ alloy in shell shape to be stable in quality by a newly-developed manufacturing process. The glassy alloy exhibits excellent mechanical properties suitable for driver golf club heads. The driver golf club with the glassy alloy used for the head is confirmed to have a high coefficient of restitution. It has been commercially placed on the market.

\section{REFERENCES}

1) W. Klement, R. H. Willens and P. Duwez: Nature 187 (1960) 869-870.

2) T. Masumoto and R. Maddin: Acta Metall 19 (1971) 725-729.
3) C. H. Smith: Rapidly Solidified Alloys, ed. by H. H. Liebermann, (Marcel Dekker, Inc., New York, 1993) pp. 617-663.

4) A. Inoue: Mater. Trans., JIM 36 (1995) 866-875.

5) A. Inoue, T. Zhang and T. Masumoto: Mater. Trans., JIM 31 (1990) 177-183.

6) T. Zhang, A. Inoue and T. Masumoto: Mater. Trans., JIM 32 (1991) 1005-1010.

7) A. Peker and W. L. Johnson: Appl. Phys. Lett. 63 (1993) 2342-2344.

8) A. Inoue, T. Shibata and T. Zhang: Mater. Trans., JIM 36 (1995) 1420 1426.

9) A. Inoue: Acta Mater. 48 (2000) 279-306.

10) T. Yamaguchi, I. Tominaga, T. Iwatsubo, N. Nakagawa and M. Akao: Theoretic. Appl. Mech. 34 (1986) 153-166.

11) 1 yard $=0.9144 \mathrm{~m}$. 